of Oppenheimer's trial testimony. This recollection has been shown by historians to be incorrect: Teller had already significantly contributed to the anti-Oppenheimer case.

Teller's testimony was not the decisive point of the hearing - the inevitable outcome of which was to deny Oppenheimer's appeal and thus exclude him from government circles - but it was the psychological coup de grâce. Those who knew Oppenheimer found Teller's remarks preposterous. From then on, many refused to acknowledge him, isolating him from the mainstream physics community. Thus began what Hargittai calls Teller's third exile; again, a description that is a stretch, because it was self-inflicted and because Teller blossomed into an influential and canny insider in US political and military circles. "Edward understood power," remarked George Keyworth, science adviser to President Ronald Reagan. "He could have written [Machiavelli's] The Prince."

Hargittai is an acute observer of Teller's personal interactions. He gives an astute reading, for instance, of Teller's letters to the German-American physicist Maria Goeppert Mayer, which ranged from physics to personal matters. Hargittai exposes Teller's half-truths and falsehoods, including his erroneous suggestion that he opposed dropping the atomic bomb on Hiroshima. Such revisionist statements might be described as 'truthy' in the sense applied by US comedian Stephen Colbert to the remarks of certain politicians - as portraying the truth they want to exist. Hargittai also points out exaggerations by Teller's critics, such as unjustified comparisons with Trofim Lysenko, the biologist who destroyed Soviet genetics by sending it on a politically thrilling but scientifically questionable crusade.

Hargittai sometimes acts too much like an umpire, evaluating claims about Teller rather than appraising him as a moral and political agent. It would have been intriguing to investigate the psychological factors at work in a person whose idea of protecting his adopted country was to damage its science base by undermining eminent people whose views were less extreme than his own. How did such an envious and petulant individual become a point person for the US military? Answering such issues would require more background knowledge than Hargittai provides about the US weapons establishment, which itself used Teller as much as he used it. It would also require an understanding of the pernicious US preoccupation with security that often moves its leaders to damage their country in order to save it.

Robert P. Crease is professor of philosophy at Stony Brook University, New York 11794, USA, and author of The Great Equations. e-mail:rcrease@notes.cc.sunysb.edu

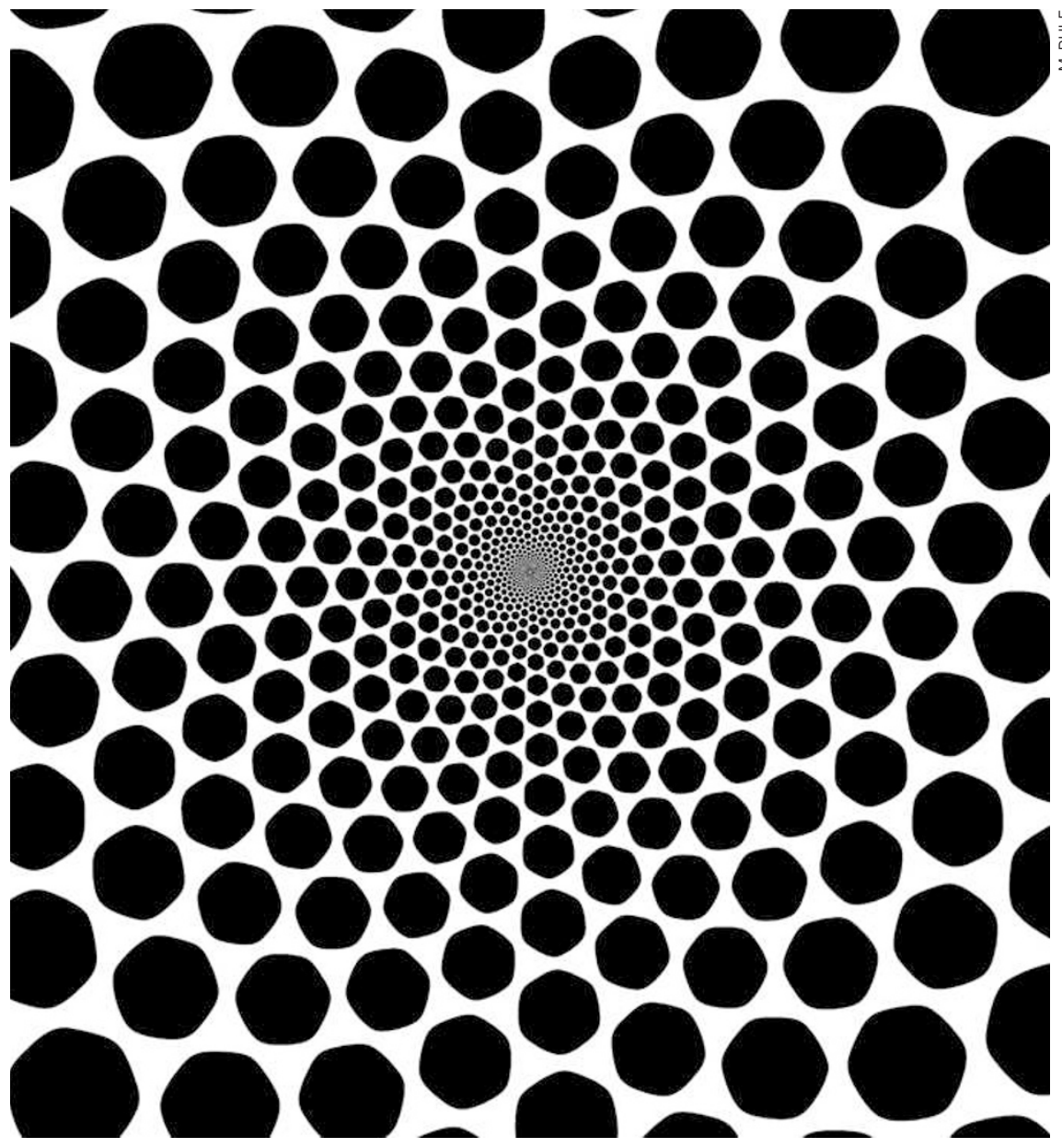

The visual disturbances seen by some people with migraines can be modelled mathematically.

\title{
NEUROSCIENCE
}

\section{Patterns from the brain}

\section{Vincent A. Billock recommends an introduction to the mathematics of geometric hallucinations.}

U ntil recently, biologists treated theory as a reward, claimed after a lifetime of labour in experiment and observation. Yet, within just a few generations, theorists in neuroscience have begun to resemble their cousins in physics, choosing to specialize in theory early in their careers. The focus of theoretical neuroscience has shifted in that time towards complexity: from models of nerve conduction to an emphasis on the dynamics of nonlinear neural interactions. Bard Ermentrout, a biophysicist, had much to do with that transformation, which is highlighted in his and mathematician David Terman's textbook, Mathematical Foundations of Neuroscience.

Terman and Ermentrout share an interest in the failure modes of neural systems. Nonlinear dynamic aspects are often only revealed when neural systems are pushed to the edges of their performance abilities. Migraines, strobe lights and drug intoxication can all cause geometric hallucinations: Ermentrout studies these as well as the illusions produced by viewing moving images during electric reti-

"Should maths
be conveyed
separately
to students
who show
theoretical
aptitude, or
mixed in as
digressions
to a lecture
series?"
nal stimulation. Terman's model of image segmentation fragments noisy images (such as television static) in a manner that is reminiscent of these visual effects. However, aside from geometric hallucinations, the wilder 
sides of Ermentrout and Terman's research interests are not emphasized in the book, which is directed at a broad interdisciplinary audience.

The traditional material on membrane biophysics, cable theory and neural-spike generation models is presented first. The latter part of the book - covering the nonlinear dynamics of neural interactions - takes a balanced approach, describing models in which the correct timing of individual neural spikes is crucial, and popu-

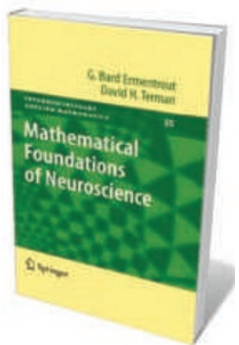

Mathematical Foundations of Neuroscience G. BARD ERMENTROUT AND DAVID H. TERMAN Springer: 2010 422 pp. $\$ 74.95$ lation models based on the firing rates of an ensemble of neurons. Rapidly evolving topics such as neural synchronization and spatially extended models are included.

Ermentrout and Terman go deeper into the mathematics of neural activity than say, Hugh Wilson's 1999 textbook Spikes, Decisions and Actions (Oxford University Press). But, unlike Wilson, they pass up most opportunities to connect the mathematics to its cognitive and perceptual consequences.

They emphasize the mathematical basics even over exciting developments in theory. For example, a strong chapter on neural noise neglects stochastic resonance - a phenomenon of nonlinear systems in which a weak signal can be amplified and optimized by noise - and its role in promoting neural pattern formation. Similarly, Terman omits his own model when describing oscillatory neural synchronization, a process that may perceptually bind together the disparate parts of a stimulus.

This tight focus raises the question of how mathematical skills should be taught across science subjects. Should they be conveyed separately to students who show theoretical aptitude, or mixed in as digressions to a science-based lecture series? Mathematical Foundations of Neuroscience falls somewhere in between: it is a good substitute for a lengthy regime of abstract maths classes, but it is also well integrated into the field of neuroscience. Ermentrout and Terman's book conveys much of the advanced mathematics used in theoretical neuroscience today.

Vincent A. Billock is a visiting senior fellow with the US National Research Council at the US Air Force Research Laboratory, Building 248, Wright-Patterson Air Force Base, Ohio 45433, USA.

e-mail:vincent.billock.ctr@wpafb.af.mil

\section{Books in brief}

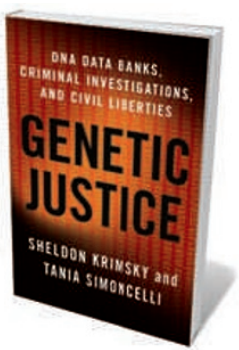

Genetic Justice: DNA Data Banks, Criminal Investigations, and Civil Liberties

Sheldon Krimsky and Tania Simoncelli COLUMBIA UNIVERSITY PRESS 448 pp. \$29.95 (2010)

Governments worldwide are increasingly storing the DNA profiles of their populations. Medical ethics advisers Sheldon Krimsky and Tania Simoncelli describe the US situation, placing those trends in context with precedents in other nations. They examine ethical issues such as holding DNA from juveniles and broadening searches to include a suspect's family members. The fallibility of DNA profiling, they suggest, has major implications for criminal justice.

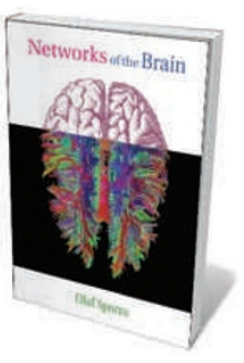

Networks of the Brain

Olaf Sporns THE MIT PRESS 375 pp. $\$ 40$ (2010)

The study of brain connectivity increasingly borrows from theories of complex systems. Points of contact between these disciplines are explored in this wide-ranging book by neuroscientist Olaf Sporns. From individual cells and synapses to whole cognitive systems, he explains how networks connect levels of organization in the brain and how their structures link to brain function. As well as documenting the latest developments - using an informal approach that does not rely on mathematics - he traces the historical roots of the field.

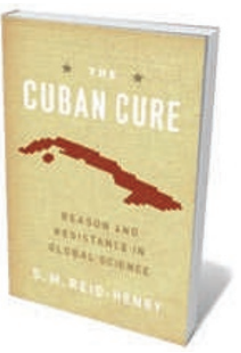

The Cuban Cure: Reason and Resistance in Global Science Simon M. Reid-Henry UNIVERSITY OF CHICAGO PRESS 216 pp. $\$ 39$ (2010)

Since Fidel Castro took over the nation in 1959, Cuba has taken science seriously. Its biotechnology programme is especially advanced - it has produced a meningitis $B$ vaccine and cuttingedge cancer therapies despite poverty and a trade embargo. Geographer Simon M. Reid-Henry examines the culture clashes that arise when biomedical scientists from Cuba work on the international stage and compete with big pharma. He asks what lessons Cuba holds for the science bases of other developing countries.

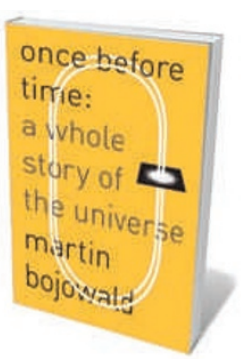

Once Before Time: A Whole Story of the Universe

Martin Bojowald KNOPF 320 pp. \$27.95 (2010)

The origin of the Universe before the Big Bang is difficult to model mathematically. Physicist Martin Bojowald describes his own work to overcome this problem using loop quantum cosmology - a model he developed a decade ago based on the theory of loop quantum gravity, which merges general relativity and quantum mechanics. He explains his search for testable hypotheses. If verified, these might show that the Big Bang was not a one-off event, but one of many recyclings of a Universe that alternately swells and contracts.

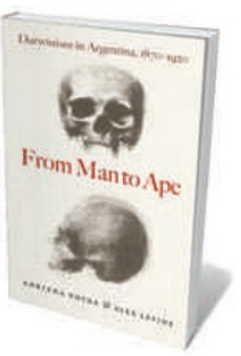

From Man to Ape: Darwinism in Argentina, 1870-1920

Adriana Novoa and Alex Levine UNIVERSITY OF CHICAGo PRESS 328 pp. $\$ 49$ (2010)

Charles Darwin's ideas about evolution were received differently in Latin America than elsewhere. Focusing on Darwin's use of analogies, science philosophers Adriana Novoa and Alex Levine explore how Argentina's culture influenced interpretations of evolution in the nineteenth century. Darwin's 'tree of life' became a 'tree of death' in the hands of one local scientist. Argentina's diverse peoples and unusual fossils also contributed alternative views of nature. 